\title{
Not All Job Demands Are Equal: Differentiating the Effects of Challenge and Hindrance Job Demands on Employee Creativity
}

\author{
$\mathrm{Xi} \mathrm{Li} \mathrm{i}^{1, \mathrm{a}}$, Cheng $\mathrm{Li}^{2, \mathrm{~b}}$ \\ ${ }^{1}$ Macau University of Science and Technology, Macau \\ ${ }^{2}$ Development and Research Institute of Guangdong Industrial, China \\ axili@must.edu.mo, bleecheng58@163.com
}

\begin{abstract}
Keywords: Challenge job demands, Hindrance job demands, Emotional exhaustion, Work engagement, Creativity
\end{abstract}

\begin{abstract}
Drawing on Job Demands-Resources (JD-R) model, we hypothesized and tested a moderated mediation process linking challenge-hindrance job demands to employee creativity. Data were obtained from 406 supervisor-subordinate dyads in a group company in China. The results showed that challenge job demands were negatively related to emotional exhaustion, but positively related to work engagement and employee creativity. Hindrance job demands were positively related to emotional exhaustion, but negatively related to work engagement and employee creativity. Emotional exhaustion and work engagement mediated the relationships between challenge-hindrance job demands and employee creativity. This study provided important insights into mechanisms about job demands on employee creativity.
\end{abstract}

\section{Introduction}

Employees are exposed to a variety of workplace demands every day, especially in an era of intense global competition and rapid change. The general assumption is that job demands are detrimental and that organizations must find ways to prevent or reduce their negative effect (Wallace, Edwards, Arnold, \& Frazier, 2009). Research in this domain is potentially valuable because stressful job demands destroy employees' well-being and organizational productivity (Podsakoff, LePine, \& LePine, 2007). Job demands are defined as those physical, psychological, social, or organizational aspects of the work that require sustained physical and/or psychological (emotional and cognitive) efforts or skills, and therefore are associated with certain physiological and/or psychological costs (Crawford, LePine, \& Rich, 2010). Dominant research has focused on the impact of job demands on employees' work outcomes and ways for managers to reduce their health impairment process (see review by Bakker, Demerouti, \& Dollard, 2008). Generally, job demands are viewed as bad or unattractive (Janssen, 2000). In spite of tremendous research in the field of job demands, recent reviews have identified several theoretical and methodological weaknesses in the literature (Crawford et al., 2010; LePine, Podsaoff, \& LePine, 2005).

The first weakness concerns the conceptualizations of job demands. Recently, researchers tend to differentiate two types of job demands, challenge job demands and hindrance job demands (Crawford et al., 2010; Wallace et al., 2009). Challenge job demands refer to requirements that produce positive feelings, personal growth, or future gains, and employees view these demands as opportunities to learn, achieve, and demonstrate competence (Podsakoff et al., 2007). Hindrance job demands, on the other hand, impede personal growth, learning, and goal attainment and are generally seen by employees as constraints, barriers, or roadblocks that hinder progress toward goals and effective performance (LePine et al., 2005). Job demands are akin to stressor and they are frequently interchangeable. However, it may create inflated correlations to incorporate the term "stress" in the response scale of the stressor measure (Jex, Beehr, \& Roberts, 1992). In other words, understanding and exploring these two types of job demands are extraordinarily important.

In the context that organizations need to be innovative to survive and prosper, employees are under the pressure from the organizations to meet high job demands and/but to demonstrate more creativity. 
The second weakness is that paucity of studies have linked job demands with employee creativity. How do job demands influence creativity? Prior research has linked challenge and hindrance job demands with employee task performance (Babakus, Yavas, \& Ashill, 2009; LePine et al., 2005), citizenship behaviors (Rodell \& Judge, 2009). The premise is important because being creative is an explicit job demand, which is important for organizational success by helping organizations develop better-quality innovative services and products which allow them to outperform competitors (Florida, 2004). Byron, Khazanchi, \& Nazarian (2010) argued that the relationship between job demands and creativity was more complex than previously assumed and pointed to the need for understanding boundary conditions that shed light on inconsistent findings.

The third weakness concerns the mechanisms through which challenge and hindrance job demands relate to employees' work outcomes. Why do job demands influence employee work outcomes? Prior literatures have explored some mediators between the relationships, such as anxiety (Rodell \& Judge, 2009), strains (Podsakoff et al., 2007), motivation (LePine et al., 2005), and work self-efficacy (Webster, Beehr, \& Christiansen, 2010). However, little research focused on the health impairment process and motivation process simultaneously as a whole. In present study, we draw on two conflicting mediators (emotional exhaustion and work engagement) in one conceptual model simultaneously. Work engagement is viewed as the positive antithesis of emotional exhaustion, or the positive side of the same psychological coin (Maslach, Schaufelli, \& Leiter, 2001). The mechanisms include a health impairment process in which two types of job demands both exhaust an employee's mental and physical resources and thus lead to burnout. Alternatively, based on distinct expectation nature, challenge job demands motivate employees toward higher work engagement, which further lead to positive work performance. In contrast, hindrance job demands are seen by employees as constraints that hinder progress toward work engagement, and then result in lower employee creativity.

\section{Literature Review and Hypotheses}

Challenge-Hindrance Job Demands, Emotional Exhaustion and Creativity. Though challenge job demands represent a positive motivating force, the nature of which was still stressor. Therefore, it is not surprising that challenge job demands were found to be positively related to emotional exhaustion (Podsakoff et al., 2007). While keeping efforts to cope with challenge job demands, employees meet with an increase in compensatory psychological and physiological costs that drain the employees' energy (Bakker \& Demerouti, 2007). As a result, employees come into a chronic state of physical and emotional depletion and feel emotionally exhausted. Similarly, Crawford et al. (2010) also argued that all job demands, whether challenges or hindrances, were positively related to burnout because the increased effort associated with the appraisal of demands and coping with them results in strain (e.g., anxiety, fatigue), which in turn, was dissatisfying and over time leading to emotional exhaustion. Emotional exhaustion originates from the burnout process and reflects a state in which one feels drained of energy and enthusiasm for work, as well as feeling that one's resources are depleted. Thus, emotional exhaustion is negatively associated with creativity. It requires energy and enthusiasm when employees attempt to try new ideas, explore novel directions, and behave creatively, since the process of exploration is difficult and risky. Accordingly, we propose that

Hypothesis 1: Emotional exhaustion will mediate the relationship between challenge job demands and creativity.

Hindrance job demands, as physiological and psychological costs, interfere with or hinder an individual's ability to achieve valuable goals. The presence of hindrance job demands is predicted to be positively related to emotional exhaustion (Crawford et al., 2010). This type of job demands exhausts one's mental and physical resources and thus results in emotional impairment. Specially, when employees think things never change and situations never improve, or they find themselves in a rut with a job which they really don't care for, emotional exhaustion will emerge. Early studies have 
explored the mediating effect of emotional exhaustion between hindrance job demands and task performance, such as Babakus et al. (2009). However, not much work has examined the mediating role of emotional exhaustion that links hindrance job demands to creativity. The health impairment process can be characterized as an energy draining process, which could serve to underpin the relationships. Further, exhausted individuals have no interest in the process of development and exploration of such novel directions and ideas. They also have little vigor to deal with high level of uncertainty, ambiguity and the risk of making mistakes and arriving at impractical solutions. We posit that

Hypothesis 2: Emotional exhaustion will mediate the relationship between hindrance job demands and creativity.

Challenge-Hindrance Job Demands, Work Engagement and Creativity. Challenge job demands could also serve as stimulating roles besides their nature of energy-depleting. Because they tend to be appraised as helpful to employees' career development (e. g., potentially promoting mastery, personal growth, or future gains), challenge job demands can trigger positive emotions (e. g., eagerness, excitement, exhilaration) and problem-focused style of coping (e. g., strategizing, and increases in effort). Even though employees may at some point feel exhausted. The perceptions and beliefs of obtaining benefit in the future increase the degree to which individuals are willing to invest themselves in response to the type of job demands. Meanwhile, work engagement is viewed as the positive antithesis of emotional exhaustion, or the positive side of the same psychological coin (Maslach et al., 2001). Therefore, we expect that challenge job demands will induce work engagement. Further, work engagement can serve as the mediating role in the link between challenge job demands and creativity. Employees tend to be more creative when they work on challenging and complex tasks that are significant and intellectually intriguing (Choi, 2007). Challenging job demands increase task engagement, make the best of cognitive resources, increase positive effect (Baer \& Oldham, 2006), and motivate employees to engage in focused problem-solving strategies (Bunce \& West, 1994), all of which could enhance creativity. Thus,

Hypothesis 3: Work engagement will mediate the relationship between challenge job demands and creativity.

On the other hand, hindrance job demands reduce motivation and are harmful to personal growth/gain since they are negatively associated with employees' work engagement (Crawford et al., 2010). When confronted with this type of job demands, employees feel a lack of control, experience negative emotions, and tend to adopt an emotion-focused coping style (Babakus et al., 2009). Because they are considered to be threatening obstacles that drain energy, employees are not willing to take more efforts to invest themselves. We propose that hindrance job demands reduce employees' work engagement, which in turn lower their creativity. According to expectancy theory (Vroom, 1964), people are likely to believe that there is a negative relationship between effort expended on coping with this type of demands and also likely to believe that if these demands are met, unvalued or unexpected outcomes will occur. That means without motivation and expectation, fewer physical, cognitive, and emotional energies are available for creative thinking. Instead, simple cognitive strategies are likely to used, which result in the production of more common, less original ideas. As a result, employees pay less attention to the responsibilities of bringing up problems or complex issues. They are also less emotionally connected to the creative activities. Additionally, hindrance job demands make individuals less willingness to take risks in order to foster interests and fascination with novelty. When novel ideas are resisted or rejected, they easily give up. Therefore,

Hypothesis 4: Work engagement will mediate the relationship between hindrance job demands and creativity. 


\section{Method}

Procedure and Sample. Respondents were employees and their immediate supervisors who came from a group company located in Guangzhou City in South China. By design, participants of the survey should be selected from professional positions that require substantial creativity in order to be effective at work, such as professionals in R\&D expansion. Of the 500 dyads questionnaires that were sent in the survey, 457 dyads responded, resulting in a $91.4 \%$ response rate. Only 406 of the 457 dyads that responded to the survey were retained for analysis. The cases that were removed from the study were incomplete and missing a significant number of responses across multiple variables. A total of 179 males and 227 females comprised the sample with ages ranging from 22 to 55 years $(\mathrm{M}=$ 29.45; $\mathrm{SD}=6.00)$, and education years ranged from 9 to 19 years $(\mathrm{M}=15.74$; $\mathrm{SD}=1.81)$. The married status of the sample included single $(n=229)$, and married $(n=177)$. Working hours per week ranged from 8-70 hours $(\mathrm{M}=46.13 ; \mathrm{SD}=9.73)$.

Measures. The questionnaires were originally constructed in English but were administrated in Chinese. We used a standard translation and back-translation procedure to ensure the equivalence of the measures in the Chinese and the English language versions of the questionnaire. Challenge job demands were assessed with 12-items (4-dimension) scale by us in the previous pilot study. The Cronbach's alpha was .86, which was greater than .70. Hindrance job demands were also measured by using 17-item scale that had been developed by us in the pilot study. The four dimensions hassles, role overload, role conflict and role ambiguity (Cronbach's alpha=.86). Emotional exhaustion was measured by using an inventory which has been developed as a subscale from the Maslach Burnout Inventory (MBI) (Maslach \& Jackson, 1986). Cronbach’s alpha for its scale was .87. Work engagement was measured using the 9-item version of the Utrecht Work Engagement Scale (Schaufeli, Bakker, \& Salanova, 2006). The three dimensions vigor, dedication, and absorption were each measured with three items (Cronbach's alpha=.89). Creativity was measured by adapting a 13-item scale used in previous studies (Zhou \& George, 2001) (Cronbach’s alpha=.93).

\section{Results}

Descriptive Statistics and Correlations. All variables had acceptable reliabilities, with Cronbach's alpha coefficients of .70 or higher. As shown, challenge job demands were positively correlated with emotional exhaustion $(\mathrm{r}=.10, \mathrm{p}<.05)$, work engagement $(\mathrm{r}=.31, \mathrm{p}<.001)$, and creativity $(\mathrm{r}=.14, \mathrm{p}<.01)$. Hindrance job demands were positively correlated with emotional exhaustion $(\mathrm{r}=.60$, $\mathrm{p}<.001$ ), negatively correlated with work engagement $(\mathrm{r}=-.34, \mathrm{p}<.001$ ), and creativity ( $\mathrm{r}=-.23$, $\mathrm{p}<.001)$. Furthermore, emotional exhaustion were negatively correlated with creativity $(\mathrm{r}=-.17$, $\mathrm{p}<.01)$. Work engagement were positively correlated with creativity $(\mathrm{r}=.24, \mathrm{p}<.001)$.

Structural Equation Modeling Analysis. Before testing our hypotheses, we adopted Anderson \& Gerbing's (1988) comprehensive, two-step analytical strategy to test the hypothesized model. The measurement model results indicated a good fit to the data $\left(\chi^{2}[132]=514.68, p<.001\right.$; CFI $=.93$, $\mathrm{NFI}=.91$, IFI=.93, RMSEA=.084). They provided evidence that further examination of the structural model was justified. Structural equation modeling (SEM) was used to examine the hypothesized model. To help elucidate the relationships among the various mediating variables in the hypothesized model, we conducted an effects decomposition to further understand the direct and indirect effects (Brown, 1997). Specific indirect effects represent the portion of the total effect that works through a single intervening variable (Fox, 1980). Our effects decomposition yielded a coefficient () for the indirect effect of challenge job demands on creativity through emotional exhaustion was .02 ( $<<.001)$, which accounted for 14.29 percent of the total effect. The coefficient for the indirect effect of challenge job demands on creativity through work engagement was $.12(\mathrm{p}<.001)$, and the effect accounted for 85.71 percent of the total effect (See Table 3). Similarly, the coefficient for the indirect effect of hindrance job demands on creativity through emotional exhaustion was $-.09(p<.05)$, which accounted for 40.91 percent of the total effect. The coefficient for the indirect effect of hindrance job 
demands on creativity through work engagement was $-.13(\mathrm{p}<.001)$, and the effect accounted for 59.09 percent of the total effect.

\section{Summary}

Our findings provide evidence that it is appropriate for managers to differentiate between two categories of job demands when considering stress management practices. Organizations should concern with reducing the negative effects of hindrance job demands and increasing the positive influences of challenge job demands. In the process, more benefit could be obtained from paying attention to the level of challenging and hindering situations in the workplace. Most of all, employees' creativity is an important outcome. In order to keep up with the rapid pace of today's organizations, employees need to be allowed to work at their highest creative potential. It is imperative for organizations to learn how to maximize each employee's ability to be creative.

However, managing challenge job demands deserves a bit more thought, because the results showed that this type of demands had benefits and costs in terms of behaviors simultaneously (Crawford et al., 2010). Although the benefits (energy stimulating process) outweigh the costs (health impairment process), organizations and managers also need to find ways to reduce any potential negative effects even further. Because the main aim of an organization should be to ensure the job demands such that employees can fulfill them without damaging their health (Bakker et al., 2008). If employees' energy depleting such as emotional exhaustion could not be well controlled, the results are not merely decrease performance but also destroy employees' health in the long time.

\section{References}

[1] E. Babakus, U. Yavas, \& N. J. Ashill. (2009). The role of customer orientation as a moderator of the job demand-burnout-performance relationship: A surface-level trait perspective. Journal of Retailing, 85(4), 480-492.

[2] M. Baer, \& G. R. Oldman. (2006). The curvilinear relation between experienced creative time pressure and creativity: Moderating effects of openness to experience and support for creativity. Journal of Applied Psychology, 91(4), 963-970.

[3] A. B. Bakker, \& E. Demerouti. (2007). The job demands-resources model: State of the art. Journal of Managerial Psychology, 22(3), 309-328.

[4] A. B. Bakker, E. Demerouti, \& M. F. Dollard. (2008). How job demands affect partners' experience of exhaustion: Integrating work-family conflict and crossover theory. Journal of Applied Psychology, 93(4), 901-911.

[5] D. Bunce, \& M. West. (1994). Changing work environments, Innovative coping responses to occupational stress. Work and Stress, 8(4), 319-331.

[6] K. Byron, S. Khazanchi, \& D. Nazarian. (2010). The relationship between stressors and creativity: A meta-analysis examining competing theoretical models. Journal of Applied Psychology, 95(1), 201-212.

[7] J. N. Choi. (2007). Change-oriented organizational citizenship behavior: Effects of work environment characteristics and intervening psychological processes. Journal of Organizational Behavior, 28(4), 467-484.

[8] E. R. Crawford, J. A. LePine, \& B. L. Rich. (2010). Linking job demands and resources to employee engagement and burnout: A theoretical extension and meta-analytic test. Journal of Applied Psychology, 95(5), 834-848.

[9] R. Florida. (2004). America's looming creativity crisis. Harvard Business Review, 82(10), 122-136. 
[10] O. Janssen. (2000). Job demands, perceptions of effort-reward fairness and innovative work behavior. Journal of Occupational and Organizational Psychology, 73(3): 287-302.

[11] S. M. Jex, T. A. Beehr, \& C. K. Roberts. (1992). The meaning of occupational stress items to survey respondents. Journal of Applied Psychology, 77(5), 623-628.

[12] J. A. LePine, N. P. Podsaoff, \& M. A. LePine. (2005). A meta-analytic test of the challenge stressor-hindrance stressor framework: An explanation for inconsistent relationships among stressors and performance. Academy of Management Journal, 48(5), 764-775.

[13] C. Maslach, \& S. E. Jackson. Maslach burnout inventory (2nd ed.). Palo Alto, CA: Consulting Psychologists Press, 1986.

[14] C. Maslach, W. B. Schaufelli, \& M. P. Leiter. (2001). Job burnout. Annual Review of Psychology, 52(1), 397-422.

[15] N. P. Podsakoff, J. A. LePine, \& M. A. LePine. (2007). Differential challenge stressor-hindrance stressor relationships with job attitudes, turnover intentions, turnover, and withdrawal behavior: A meta-analysis. Journal of Applied Psychology, 92(2), 438-454.

[16] J. B. Rodell, \& T. A. Judge. (2009). Can “good” stressors spark "bad” behaviors? The mediating role of emotions on links of challenge and hindrance stressors with citizenship. Journal of Applied Psychology, 94(6), 1438-1451.

[17] W. B. Schaufeli, A. B. Bakker, \& M. Salanova. (2006). The measurement of work engagement with a short questionnaire: A cross-national study. Educational and Psychological Measurement, 66(4), 701-716.

[18] V. Vroom. Work and Motivation. New York: Wiley, 1964.

[19] J. C. Wallace, B. D. Edwards, T. Arnold, \& M. L. Frazier. (2009). Work stressors, role-based performance, and the moderating influence of organizational support. Journal of Applied Psychology, 94(1), 254-262.

[20] J. R. Webster, T. A. Beehr, \& N. D. Christiansen. (2010). Toward a better understanding of the effects of hindrance and challenge stressors on work behavior. Journal of Vocational Behavior, 76(1), 68-77.

[21] J. Zhou, \& J. M. George. (2001). When job dissatisfaction leads to creativity: Encouraging the expression of voice. Academy of Management Journal, 44(4), 682-696.

[22] J. C. Anderson, \& D. W. Gerbing. (1988). Structural equation modeling in practice: A review and recommended two step approach. Psychological Bulletin, 103(3), 411-423. 